\title{
Democracia e participação na gestão dos recursos hídricos no Brasil
}

\author{
Pedro Roberto Jacobi \\ Universidade de São Paulo (USP)
}

\author{
Fabiana Barbi \\ Universidade de São Paulo (USP)
}

\section{Democracia e participação na gestão dos recursos hídricos no Brasil}

Resumo: Este artigo aborda o fortalecimento do espaço público e a abertura da gestão pública à participação da sociedade civil na elaboração de suas políticas públicas. Trata, também, da sempre complexa e contraditória institucionalização de práticas inovadoras que marcam rupturas com a dinâmica predominante em áreas e setores da administração, especificamente na gestão ambiental. Apresenta uma reflexão focalizada na gestão pública compartilhada dos recursos hídricos no Brasil e nas transformações qualitativas na relação entre Estado e sociedade, como referências de inflexão e reforço das políticas públicas centradas na ampliação da cidadania. Assinala, nas conclusões, os impactos das práticas participativas, que, apesar de controversas, apontam para uma nova qualidade de vida, que abre novos espaços sociopolíticos e influencia qualitativamente na transformação do estado atual da gestão de recursos hídricos no Brasil.

Palavras-chave: gestão de recursos hídricos, democracia, participação.

\section{Democracy and Participation in the Management of Water Resources in Brazil}

Abstract: This article analyzes the strengthening of public space and the opening of public management to participation of civil society in the preparation of public policies. It also analyzes the always complex and contradictory institutionalization of innovative practices that establish ruptures with the predominant dynamic in areas and sectors of administration, specifically in environmental management. It analyzes the shared public management of water resources in Brazil and the qualitative transformations in the relationship between State and society, as references of inflection and reinforcement of public policies based on expansion of citizenship. The conclusion summarizes the impacts of participative practices, which despite controversies, point to a new quality of life, that opens new sociopolitcal spaces and qualitatively influences the transformation of water resources management in Brazil.

Key words: water resources management, democracy, participation. 


\section{Participação social nas políticas públicas no Brasil}

No Brasil, a luta pela conquista de espaços para aumentar a participação social é sem dúvida um dos aspectos mais desafiadores para a análise sobre os alcances da democracia. As experiências de deliberação participativa desde o início dos anos 1980 estão associadas à capacidade que os movimentos sociais tiveram de explicitar demandas relacionadas principalmente com a distribuição de bens públicos e também em menor escala na formulação de políticas públicas. A participação citadina se configura nas práticas dos movimentos organizados, das entidades civis ou simplesmente de cidadãos, mobilizados através de fóruns e espaços públicos múltiplos e diferenciados, nos quais direitos e demandas coletivas são apresentados como questões a serem incluídas na agenda pública. Os movimentos sociais organizados, apesar dos argumentos em torno da sua fragmentação, dispersão e fragilidade, colocaram na agenda da democratização a necessidade de garantir direitos sociais básicos como parte componente da conquista de cidadania. A constituição de cidadãos, consubstancia-se a partir da mudança das práticas sociais existentes e na sua substituição por novas formas de referências, que têm na participação um componente essencial. Isto ocorre, na medida em que o impacto dessas práticas na constituição de uma arena societária em expansão permite, aos sujeitos sociais ativos, perceber que a multiplicação de práticas democratizantes pode gerar mudanças nas suas vidas cotidianas (JACOBI, 2000).

O desafio maior dos movimentos sociais é o de romper com a lógica prevalecente pautada pelo clientelismo e troca de favores, e para tanto diversas experiências (DAGNINO, 2002; AVRITZER; NAVARRO, 2003; COELHO; NOBRE, 2004) têm mostrado que é possível criar espaços públicos democráticos e plurais de articulação e participação, nos quais os conflitos se tornam visíveis e as diferenças se confrontam, enquanto bases constitutivas da legitimidade dos diversos interesses em questão. A participação da sociedade civil na gestão pública introduz uma mudança qualitativa na medida em que incorpora outros níveis de poder além do Estado.

Os arranjos participativos, a partir da Constituição de 1988, abrem espaço para a prática da democracia participativa (DAGNINO, 2002; SANTOS; AVRITZER, 2002; JACOBI, 2003). A revitalização da sociedade civil, desde meados da década de 1980, reflete-se no aumento do associativismo e na presença dos movimentos sociais organizados que se explicitam na construção de espaços públicos que pressionam pela ampliação e democratização da gestão estatal (AVRITZER, 2002). Na década de 1990, a participação é amparada e institucionalizada den- tro dos marcos das democracias representativas, como é o caso do orçamento participativo (AVRITZER; NAVARRO, 2003). A participação popular se transforma no referencial de ampliação de possibilidades de acesso dos setores populares aos serviços urbanos básicos e equipamentos sociais, dentro de uma perspectiva de desenvolvimento da sociedade civil e de fortalecimento dos mecanismos democráticos. Isto também se configura como uma garantia da execução eficiente de programas de compensação social no contexto das políticas de ajuste estrutural, de liberalização da economia e de privatização do patrimônio do Estado.

A possibilidade de ocorrer uma mudança na institucionalidade pública está associada às demandas que se estruturam na sociedade, e nesse sentido, a esfera pública representa a construção da viabilidade ao exercício da influência da sociedade nas decisões públicas, assim como coloca uma demanda de publicização no Estado. As práticas sociais que formam a cidadania, conforme Putnam (1994), constituem-se em um espaço privilegiado para o desenvolvimento da responsabilidade pessoal, da obrigação mútua e da cooperação voluntária. A ampliação da esfera pública traz uma demanda à sociedade em termos de obter uma maior influência sobre o Estado, tanto como sua limitação, assumindo que a autonomia social supõe transcender as assimetrias na representação social, assim como modificar as relações sociais em favor de uma maior auto-organização social (JACOBI, 2000).

A constituição de formas alternativas de gestão da coisa pública, como é o caso do orçamento participativo, simultaneamente com a ampliação do espectro de problemas tratados publicamente está associada à emergência de novos atores coletivos, como é o caso do movimento ambientalista e ecologista. Para Bobbio (1987, apud JACOBI, 2000), o desenvolvimento de diversas formas de participação dentro das opções políticas e o crescimento das formas de organização de massa que exercem direta ou indiretamente algum poder político podem ser entendidos não só no sentido de Estado que permeou a sociedade, mas também no sentido de Estado permeado pela sociedade. Os dois processos representam, segundo o autor, as duas figuras do cidadão - o participante e o protegido - que estão em conflito entre si, às vezes na mesma pessoa. E, portanto, sociedade e Estado atuam como "dois momentos necessários, separados, mas contíguos, distintos, mas interdependentes do sistema social em sua complexidade e em sua articulação interna" (BOBBIO, 1987 apud JACOBI, 2000, p.13).

$\mathrm{Na}$ abordagem habermasiana foca-se o tema da esfera pública como caixa de ressonância dos problemas a serem organizados pelo sistema político. Para Habermas (ARATO; COHEN, 1994), as soci- 
edades modernas têm uma imagem multifacetada, na qual a relação entre si, de dois subsistemas diferenciados (Estado e mercado) operam a partir de lógicas diferentes, e constituem o ponto focal de indissociáveis tensões.

Habermas (1984) aponta a esfera pública como ponto de encontro e local de disputa entre os princípios divergentes de organização da sociabilidade. Onde os movimentos sociais se constituiriam nos atores que reagem à reificação e burocratização dos domínios de ação estruturados comunicativamente, defendendo a restauração das formas de solidariedade postas em risco pela racionalização sistêmica.

Os agentes sociais que se desenvolvem na sociedade civil após 1970, à revelia do Estado, criaram novos espaços e formas de participação e relacionamento. Espaços que foram construídos pelos movimentos populares e pelas diversas instituições da sociedade civil, articulando demandas, alianças de resistência popular e lutas pela conquista de direitos civis e sociais. Muitos movimentos apontam, a partir da reposição do coletivo, para uma qualidade diferenciada de participação na gestão pública, onde a representação não resume todo o esforço de organização. Os movimentos manifestam uma identidade que se concretiza a partir da construção coletiva de uma noção de direitos que, relacionada diretamente com a ampliação do espaço de cidadania, dá lugar ao reconhecimento público dos direitos (JACOBI, 2000, 2000a).

As reflexões sobre a cidadania, no Brasil, centram-se nos obstáculos ao seu desenvolvimento, decorrentes da cultura política tradicional, e nas perspectivas da sua transformação. A nova dimensão da cidadania inclui, de um lado, a constituição de cidadãos enquanto sujeitos sociais ativos, e de outro lado, para a sociedade como um todo, um aprendizado de convivência com esses cidadãos emergentes que recusam permanecer nos lugares que lhes foram definidos social e culturalmente (DAGNINO, 1994).

No período da transição pós-democrática no Brasil, e por força das pressões de uma sociedade civil mais ativa e mais organizada, foram criados novos espaços públicos de interação, e, principalmente, de negociação. Nesse contexto, a participação social emerge principalmente como referencial de rupturas e tensões e as práticas participativas, associadas a uma mudança qualitativa da gestão, assumem visibilidade pública e repercutem na sociedade.

A ampliação de canais de representatividade dos setores organizados para atuarem junto aos órgãos públicos, enquanto conquista dos movimentos organizados da sociedade civil, é parte componente do processo de transformação político-institucional.Isto caracteriza a potencialidade de constituição de sujeitos sociais identificados por objetivos comuns para transformar a gestão da coisa pública, configurando a construção de uma lógica de gestão com parti- cipação social, o que representa uma nova institucionalidade.

Assim, a implementação de políticas públicas, pautadas pelo componente participativo, relacionase com as mudanças na matriz sociopolítica prevalecente, que se baseia em uma lógica verticalizada. Isto implica num maior questionamento sobre o papel do Estado como principal agente indutor das políticas sociais. A noção de participação é pensada principalmente pela ótica dos grupos interessados e não apenas da perspectiva dos interesses globais definidos pelo Estado. O principal desafio que se colocava era o de construir uma ordem societária baseada na articulação da democracia política com a participação social, representada por uma maior permeabilidade da gestão às demandas dos diversos sujeitos sociais e políticos. A ênfase é na articulação entre a implantação de práticas descentralizadoras e uma engenharia institucional que concilia participação com heterogeneidade, e formas mais ativas de representatividade. Observe-se que os complexos vínculos entre representação e participação abrem o Estado a um conjunto de organizações sociais, admitindo a tensão política como método decisório, e diluindo, na medida do possível, as práticas autoritárias e patrimonialistas.

Os diferentes tipos de conselhos gestores de políticas públicas - saúde, educação, assistência social, habitação, meio ambiente, recursos hídricos - configuram a existência de um espaço público de composição plural e paritária entre Estado e sociedade civil de natureza deliberativa. Apesar de estes conselhos gestores representarem arranjos institucionais inovadores, as dúvidas se situam quanto à sua capacidade de constituírem-se em práticas inovadoras na gestão pública e também quanto a garantirem a efetiva democratização nos procedimentos de gestão.

\section{Participação da sociedade civil na gestão ambiental compartilhada}

Os mecanismos para a democracia deliberativa, entendida como modelo ou ideal de justificação do exercício do poder político pautado no debate público entre cidadãos livres e em condições iguais de participação e relacionados com questões ambientais, avançaram. Entretanto, ainda não incorporaram os grupos sociais normalmente excluídos dos mecanismos tradicionais de deliberação como atores com presença nos processos decisórios. Isto decorre do fato que estes grupos ainda não possuem os recursos econômicos e sociais e as informações que permitiriam sua participação nas atividades que permeiam processos decisórios em torno de questões ambientais.

As relações entre Estado e sociedade civil, como espaço de construção de alianças e cooperação, são 
traspassadas por conflitos que se originam do impacto das assimetrias sociais e de seus impactos no meio ambiente e das formas de resistência, organização e participação dos diversos atores envolvidos. Os três mecanismos mais relevantes para assuntos ambientais no Brasil são os conselhos de meio ambiente, os relatórios de impacto ambiental e as audiências públicas, devendo ressaltar-se o significado que as assimetrias de poder e informação têm no processo.

Dentro desta perspectiva de governança, no Brasil existem instrumentos de participação previstos na Constituição, tais como o projeto de lei de iniciativa popular, o referendo e o plebiscito. Além desses instrumentos, a Constituição prevê outros meios de participação, como é o caso dos conselhos comunitários, onde representantes da população podem participar de decisões nos campos da educação, saúde, direitos da criança e do adolescente, meio ambiente e as audiências públicas, onde a população deve ser informada e ouvida sobre projetos e iniciativas do Legislativo e do Executivo, ou sobre decisões que este deve tomar.

Na esfera do Executivo há diferentes espaços para a participação do cidadão. Inicialmente, cumpre destacar o papel dos Conselhos do Meio Ambiente. É garantida a participação dos cidadãos nos conselhos existentes nos níveis federal, estadual e municipal, estes últimos presentes na grande maioria das unidades da federação e em muitos municípios brasileiros. Esses conselhos costumam ter em sua composição representantes de entidades ambientalistas, e de outros segmentos da sociedade civil, tais como representantes dos trabalhadores, do setor produtivo, das universidades, dentre outros. Alguns desses conselhos têm a função de regulamentar leis, o que torna a participação nesses espaços ainda mais importante para os diferentes segmentos com interesse na matéria de preservação ambiental. Outros têm função consultiva, e propiciam que a sociedade apresente seu ponto vista na formulação de políticas públicas e programas.

Nos últimos dez anos, o país aperfeiçoou a legislação de proteção à biodiversidade e avançou na legislação ambiental em geral, por exemplo, tornando crime as agressões ao meio ambiente (Lei Crimes Ambientais - 9.605/98 de 12 de fevereiro de 1998). Também criou o Sistema Nacional de Unidades de Conservação (Lei 9.985 de 18 de julho de 2000 e Decreto 4.340 de 22 de agosto de 2002). Ocorre tam- bém o surgimento e fortalecimento de numerosos conselhos consultivos e deliberativos como parte componente, em várias áreas e em todos os níveis (federal, estadual e municipal) com a participação ativa de representantes de ONGs e movimentos sociais. As instâncias de gestão nas quais participam estes atores são os Conselhos de Meio Ambiente, os Comitês de Bacias Hidrográficas (CBHs) e as Áreas de Proteção Ambiental (APAs). Mas, em muitos casos, têm pouca influência no processo decisório, e a representação tem caráter bastante contraditório.

A criação do Sistema Nacional do Meio Ambiente (SISNAMA) e do Conselho Nacional do Meio Ambiente (CONAMA) incentivou significativamente a participação da sociedade civil nas atividades de proteção ambiental e a promover importantes mudanças no desenvolvimento da legislação. Os representantes da sociedade civil participam praticamente de todas as decisões em todos os conselhos e comitês gestores do Ministério do Meio Ambiente.

O sistema ambiental colegiado implementado no Brasil possibilita a internalização da questão ambiental nas políticas estaduais e municipais, quando existentes. Entretanto, os alcances quanto ao envolvimento dos movimentos sociais e organizações comunitárias têm sido muito desiguais. Observa-se que, tanto nos conselhos estaduais quanto nos municipais, com significativas diferenças entre regiões, ainda prevalecem as decisões definidas pela presença muitas vezes majoritária da representação governamental.

\section{Inovação na gestão de recursos hídricos: o compartilhamento das decisões}

À medida que aumentam os efeitos da degradação ambiental sobre a disponibilidade de recursos hídricos, a gestão de bacias hidrográficas assume crescente importância no Brasil. Ocorrem importantes avanços no setor de recursos hídricos ao longo dos últimos vinte anos, sendo que o mais significativo é a mudança de uma gestão institucionalmente fragmentada para uma legislação integrada e descentralizada, principalmente com a edição da Lei Federal n. 9.433, em 8 de janeiro de 1997 (BRASIL, 2007), e a criação da Agência Nacional de Águas (ANA), em 2000. Esta reorganização do sistema substitui práticas profundamente ar- 
raigadas de planejamento tecnocrático e autoritário. Devolve-se o poder para as instituições descentralizadas de bacia, e isto implica em promover processos de negociação entre os diversos agentes públicos, usuários e sociedade civil organizada.

A bacia hidrográfica é adotada como unidade regional de planejamento e gerenciamento das águas, o que resultou na delimitação de Unidades de Gerenciamento de Recursos Hídricos, cujos órgãos consultivos e deliberativos de gerenciamento são denominados Comitês de Bacias Hidrográficas (CBHs). O sistema está baseado no tripé descentralização, participação e integração, e a ênfase é quanto aos aspectos qualidade e quantidade das águas através de ações que promovam os usos múltiplos dos recursos hídricos. O processo ainda está em consolidação, e a prioridade dos organismos de bacia centrase na criação dos instrumentos necessários para a gestão. O sistema define uma política participativa e um processo decisório aberto aos diferentes atores sociais vinculados ao uso da água, nos quais se revêem as atribuições do Estado, o papel dos usuários e o próprio uso da água. A gestão descentralizada de cada bacia hidrográfica pelos respectivos comitês, subcomitês e agências, e a instituição da cobrança pelo uso do recurso como um dos principais instrumentos de atuação destes órgãos são os principais aspectos que devem ser destacados.

Trata-se de uma concepção de gestão pública colegiada, com negociação sociotécnica, através dos CBHs (GUIVANT; JACOBI, 2003), na qual a legislação de recursos hídricos reserva à sociedade civil uma responsabilidade central na condução da política e da gestão desses recursos. Cabe aos usuários da água organizar-se e participar ativamente dos comitês, defender seus interesses quanto aos preços a serem cobrados pelo uso, assim como sobre a aplicação dos recursos arrecadados e sobre a concessão justa das outorgas dos direitos de uso. Convém observar que isto implica em complexos processos de negociações e resolução de conflitos diversos (JACOBI, 2004, p. 272). Como a institucionalização plena ainda não ocorreu, o déficit institucional, somado à não concreção da cobrança pelo uso da água, dificulta a viabilização do processo, na medida em que tanto a cobrança como a outorga são vistas como instrumentos fundamentais de controle e realização de políticas.

Os alcances das experiências têm sido desiguais, destacando a constituição de organismos colegiados de tomada de decisão. Em 2007, existem cadastrados: 132 Comitês Estaduais, 7 Comitês Federais e 29 Consórcios Intermunicipais (REBOB, 2007).

Na lógica do colegiado, os atores envolvidos atuam tendo um referencial sobre seu papel, responsabilidades e atribuições no intuito de neutralizar práticas predatórias, orientadas pelo interesse econômico ou político. Isto facilita uma interação mais transparente e permeável no relacionamento entre os diferentes atores envolvidos - governamentais, empresariais e usuários. E também limita as chances de abuso do poder, entretanto não está isento, necessariamente, da manipulação de interesses pelo executivo, o que dependerá principalmente da capacidade de organização dos segmentos da sociedade civil e do fortalecimento da sua finalidade coletiva (JACOBI, 2004).

Os avanços têm sido bastante desiguais e isto revela a complexidade na implementação destas engenharias institucionais, baseadas na criação de condições efetivas para multiplicar experiências de gestão participativa que reforçam o significado da publicização das formas de decisão e de consolidação de espaços públicos democráticos. As mudanças estão associadas à superação das assimetrias de informação e à afirmação de uma nova cultura de direitos. Trata-se de experiências inovadoras que fortalecem a capacidade de crítica e de envolvimento de todos os segmentos. Ressalte-se a participação dos setores de baixa renda através de um processo pedagógico e informativo de base relacional, assim como a capacidade de multiplicação e aproveitamento do potencial dos cidadãos no processo decisório. As mudanças em curso representam uma possibilidade efetiva de transformação da lógica de gestão da administração pública nos estados e municípios, abrindo um espaço de interlocução muito mais complexo e ampliando o grau de responsabilidade de segmentos que sempre tiveram participação assimétrica na gestão da coisa pública.

A mudança de perspectiva na lei 9.433/1997 (BRASIL, 2007) envolve uma politização da gestão dos recursos hídricos. Este uso do conceito de política não se refere à política partidária, mas fundamentalmente a uma política abrangente, envolvendo a sociedade civil em processos de consulta e decisórios na gestão da água. Esta orientação corresponde a uma tendência internacional, conseqüiência dos graves problemas na qualidade e quantidade da água disponível no planeta, ocasionados pela forma como foram geridos os recursos hídricos.

A consolidação do processo de gestão se encontra, na maioria dos casos, ainda em fase embrionária, sendo que a prioridade dos organismos de bacia é a implantação dos instrumentos necessários para a gestão.

$\mathrm{O}$ estilo de gestão se transforma. A influência de fatores não apenas técnicos, mas também de caráter político, econômico e cultural torna o processo muito mais complexo, e o estilo de gestão que tende a prevalecer obedece a uma lógica sociotécnica. As relações de poder são parte de um processo que envolve debates e negociações conjuntas entre leigos e peritos. Assim, a gestão colegiada tende a definir uma dinâmica que permite aos atores integrar suas práti- 
cas. Isto ocorre através de negociações sociotécnicas que substituem uma concepção tecnocrática no intuito de ajustar interesses e propostas nem sempre convergentes, mas articulados para um objetivo comum (GUIVANT; JACOBI, 2003).

Em muitos comitês, o fato dos diversos atores envolvidos na dinâmica territorial terem visões divergentes do processo e dos objetivos tem dificultado a busca de soluções mais equiitativas. Cabe ressaltar que numa negociação em bases sociotécnicas entre atores diferenciados, configuram-se assimetrias na situação dos atores, tanto em termos econômicos, como sociais e políticos, o que coloca a questão da capacidade de negociação e de estabelecer pactos. Dada a complexidade do processo e das dificuldades de se consolidar um parâmetro de cidadania ambiental, em muitas casos as lógicas de gestão ainda centram numa forte prevalência do componente técnico como referencial de controle.

Ao se configurar como espaço de articulação, de negociação, de debate de problemas e ao abrir espaço para a expressão e defesa dos interesses difusos, o $\mathrm{CBH}$ reduz os riscos de que o aparato público seja apropriado por interesses imediatistas e amplia as possibilidades de uma prática orientada pela negociação sociotécnica. Assim, podem articular-se interesses territoriais e necessidades técnicas, num processo aberto a negociações (JACOBI, 2004).

A presença crescente de uma pluralidade de atores através da ativação do seu potencial de participação cria cada vez mais condições de intervir consistentemente e sem tutela nos processos decisórios de interesse público. Isso legitima e consolida propostas de gestão baseadas na garantia do acesso à informação, de canais abertos para a participação que, por sua vez, são pré-condições básicas para a institucionalização do controle social. Embora se observe também a falta de participação da sociedade civil, assim como a fragilidade de muitos atores que têm muita motivação, mas lhes falta lastro institucional.

Cabe também enfatizar que, em muitos casos, o papel dos técnicos tem sido estratégico para o fortalecimento dos comitês, principalmente para que a informação possa convergir, ser sistematizada e produzir indicadores. Estes técnicos têm se ressentido freqüentemente da falta de continuidade administrativa e das dificuldades advindas da inadequação dos atuais instrumentos entre curto e longo prazo.
Um outro aspecto a destacar é o papel das redes, como um importante instrumento de cooperação que possibilita um avanço nas relações horizontais entre atores territorialmente identificados, e dinamizados no segmento da sociedade civil, estimulando a capacitação dos seus representantes. Mesmo assim, dadas as dimensões bastante diferenciadas de participação e de conflitos, coloca-se a necessidade de superar ou conviver com certos condicionantes sociopolíticos e culturais. Isto se dá na medida em que o salto qualitativo começa a ocorrer a partir de diferentes engenharias institucionais que têm uma progressiva penetração de formas públicas de negociação dentro da lógica da administração pública, renovando os potenciais do exercício da democracia.

\section{Conclusões}

O fortalecimento dos espaços deliberativos tem sido peça fundamental para a consolidação de uma gestão democrática, integrada e compartilhada. A ampliação destes espaços de participação cidadã promove um avanço qualitativo na capacidade de representação dos interesses e na qualidade e eqüidade da resposta pública às demandas sociais.

Atualmente, o maior desafio é garantir que esses espaços sejam efetivamente públicos, tanto no seu formato quanto nos resultados. A dimensão do conflito lhes é inerente, como é a própria democracia. Portanto, estes espaços de formulação de políticas, onde a sociedade civil participa, marcados pelas contradições e tensões, representam um avanço na medida em que publicizam o conflito e oferecem procedimentos de discussão, negociação e voto de forma legítima.

Através da presença crescente de uma pluralidade de atores e da ativação do seu potencial de participação, avança-se para uma atuação efetiva e sem tutela nos processos decisórios de interesse público, assegurando canais abertos para a participação. Estes canais, por sua vez, são pré-condições para a institucionalização do controle social, pois não basta assegurar legalmente à população o direito de participar da gestão ambiental, estabelecendo-se conselhos, audiências públicas, fóruns, procedimentos e práticas.

Cabe, portanto, garantir que mudanças ocorram no sistema de prestação de contas à sociedade pelos gestores públicos e privados, mudanças culturais e de comportamento. Torna-se, então, neces- 
sário modificações no paradigma prevalecente para assegurar uma cidadania efetiva, uma maior participação e avanços em políticas que promovam e ampliem ações pautadas pelo conceito de desenvolvimento sustentável.

A participação de atores qualificados e representativos assume, por conseguinte, um papel cada vez mais relevante na denúncia das contradições entre os interesses privados e os interesses públicos na construção de políticas de recursos hídricos, que favoreçam melhorias, tanto na qualidade como no acesso à água, de forma eqüitativa, e que fortaleçam valores de sustentabilidade. Trata-se, portanto, dos comitês funcionarem como espaços e canais para ampliar o compromisso com os problemas ambientais. E traduzirem em ações efetivas de uma população organizada e informada para, na qualidade de interlocutora, realmente conhecer, entender e reclamar seus direitos, e também exercer sua responsabilidade. Acrescenta-se a isto a necessidade de identificar os papéis e as responsabilidades dos diversos atores, e a necessidade de construir consensos em torno deles. Na medida em que o Estado tiver que, cada vez mais, dar respostas às políticas orientadas para o desenvolvimento sustentável, os cidadãos passarão a ser parte integrante de uma visão comum de longo prazo.

Assim sendo, a ampliação da participação está intrinsecamente vinculada à criação de espaços públicos e plurais de articulação e participação, nos quais os conflitos se tornam visíveis e as diferenças se confrontam, enquanto base constitutiva da legitimidade dos diversos interesses em jogo. Os comitês representam nessa direção uma engenharia institucional que, embora ainda pouco visível aos olhos da grande maioria da população, busca garantir espaços participativos transparentes e pluralistas, na perspectiva de sustentabilidade e justiça social, configurada pela articulação entre complexidade administrativa e democracia.

A questão que mais salta aos olhos é a necessidade de uma crescente articulação das políticas de recursos hídricos, no contexto de políticas socioambientais, com todas as esferas do governo. Seria garantida a transversalidade, o que reforçaria a formulação de políticas ambientais pautadas pela dimensão dos problemas regionais, e, em muitos casos, metropolitanos. Coloca-se, portanto, o fortalecimento de uma gestão compartilhada com ênfase na co-responsabilização na gestão do espaço público e na qualidade de vida, e mais especificamente no diálogo entre políticas de uso e ocupação do solo e gestão da água nos municípios e regiões conurbadas.

As transformações em curso nos organismos colegiados, comitês e consórcios, mostram que a implementação efetiva dos diversos instrumentos de participação na gestão compartilhada e de recursos hídricos poderá mudar os padrões de governança, estabelecendo novas mediações entre Estado e soci- edade civil, baseadas no aprimoramento de suas relações democráticas.

\section{Referências}

ARATO, A.; COHEN, J. Sociedade civil e teoria social. In: AVRITZER, L. Sociedade civil e democratização. Belo Horizonte: Del Rey, 1994.

AVRITZER, L. Democracy and the Public Space in Latin America. New Jersey: Princeton University Press, 2002.

.; NAVARRO, Z. (Org.). A inovação democrática no Brasil: o orçamento participativo. São Paulo: Cortez, 2003. v. 1.

BRASIL. Presidência da República. Legislação. Disponível em: < http://www.presidencia.gov.br/legislacao $>$. Acesso em: 26 fev. 2007.

COELHO, V. S. R. P.; NOBRE, M. Participação e deliberação: teoria democrática e experiências institucionais no Brasil contemporâneo. São Paulo: 34 Letras, 2004. v. 1.

DAGNINO, E. Os movimentos sociais e a emergência de uma nova noção de cidadania. In: .(Org.) Política e sociedade no Brasil. São Paulo: Editora Brasiliense, 1994, p.103-118.

. Sociedade civil, espaços públicos e a construção democrática no Brasil: limites e possibilidades. In: (Org.). Sociedade civil e espaços públicos no Brasil. Paz e Terra: São Paulo, 2002, p. 279-301.

GUIVANT, J.; JACOBI, P. R. Da hidrotécnica à hidropolítica: novos rumos para a regulação e gestão dos riscos ambientais no Brasil. Cadernos de Pesquisa Interdisciplinar em Ciências Humanas, Florianópolis: UFSC, n. 67, 2003.

JACOBI, P. R. Políticas sociais e ampliação da cidadania. Rio de Janeiro: Editora FGV, 2000.

. Educação, ampliação da cidadania e participação. Educação e Pesquisa, São Paulo: USP, v. 26, n. 2, jul./ dez. 2000a.

Espaços públicos e práticas participativas na gestão do meio ambiente no Brasil. Sociedade e Estado, Editora UnB, Brasília, v. 18, n. 1/2, 2003.

. A gestão participativa de bacias hidrográficas no Brasil e os desafios do fortalecimento de espaços públicos colegiados. In: COELHO, V. S. R. P.; NOBRE, M. (Org.). Participação e deliberação. São Paulo: Editora 34 Letras, 2004, p. 270-289. 
LEIS, H. Um modelo político-comunicativo para superar o impasse do atual modelo político-técnico de negociação ambiental no Brasil. In: CAVALCANTI, C. (Org.). Meio ambiente, desenvolvimento sustentável e políticas públicas. São Paulo: Cortez, 1997.

PUTNAM, R. Making Democracy Work. New Jersey: Princeton University Press, 1994.

REBOB - Rede Brasil deOrganismos de Bacia. Disponível em: $<$ www.rebob.org.br $>$. Acesso em: jan. 2007.

SANTOS, B.; AVRITZER, L. Para ampliar o cânone democrático. In: . (Org.) Democratizar a democracia. Rio de Janeiro: Civilização Brasileira, 2002, p. 39-82.

\section{Pedro Roberto Jacobi}

Doutor em Sociologia pela Universidade de São Paulo (USP)

Professor titular na Faculdade de Educação e no Programa de Pós-Graduação em Ciência Ambiental (PROCAM) na USP

Coordenador do Grupo de Pesquisa sobre Governança da Água no Brasil do PROCAM e do Laboratório de Educação e Ambiente (TEIA-USP)

\section{Fabiana Barbi}

Mestre em Ciência Ambiental pelo PROCAM-USP

PROCAM-USP: Rua do Anfiteatro, 181

Colméias, Favo 14

São Paulo - São Paulo

CEP: 05508-900 